\title{
Avaliação de fatores de risco na contaminação natural de bactérias dos gêneros Staphylococcus e Micrococcus em queijos-minas frescal
}

\section{Evaluation of risk factors in the natural contamination of bacteria of the genus Staphylococcus and Micrococcus in minas soft cheese}

Maria da Graça Fichel do Nascimento, ${ }^{*}$ Elmiro Rosendo do Nascimento, ${ }^{\star \star}$ Anna Cassia Gomes Corbia, ${ }^{\star \star \star}$

Carlos Zarden Feitosa de Oliveira****

\begin{abstract}
Resumo
Analisou-se a influência do $\mathrm{pH}$, umidade e tempo de prateleira sobre o crescimento de bactérias dos gêneros Staphylococcus e Micrococcus, em 55 queijos-minas frescal, comercializados no estado do Rio de Janeiro. $O$ crescimento bacteriano, isolado e/ou misto, de Staphylococcus e Micrococcus, obtido por metodologia padrão, em Unidades Formadoras de Colônias (UFC), foi transformado em $\log _{10}$ para as análises de estatística descritiva e regressão linear. Atribuiu-se log $=0$ (zero) para UFC $=0$. Testou-se o efeito das variáveis independentes, $\mathrm{pH}$, umidade e tempo de prateleira, isoladas e com todas as possíveis combinações, sobre as UFC obtidas. Analisando-se as variáveis isoladamente, os resultados revelaram que a umidade e tempo de prateleira tiveram pouquíssima influência na carga bacteriana $(p<0,01)$, com valores correspondentes, respectivamente, a $9,12 \%\left(r^{2}=0,0912\right)$ e $1,69 \%\left(r^{2}=0,0169\right)$. O pH teve uma influência de $\left.23,89 \%{ }^{\prime} r^{2}=0,2389\right)$ nas UFC $(p<0,01)$. A melhor combinação, que explicou cerca de $25,61 \%\left(r^{2}=0,2561\right)$ foi na análise com as três variáveis associadas. $O \mathrm{pH}$ e umidade baixos e menor tempo de prateleira, revelaram uma associação com um aumento nas UFC de Staphylococcus e Micrococcus. Os resultados da estatística descritiva e os da análise de regressão linear encontram-se tabelados.
\end{abstract}

Palavras-chave: queijo-minas, Staphylococcus, $\mathrm{pH}$, umidade, tempo de prateleira.

\begin{abstract}
The influence of $\mathrm{pH}$, humidity and shelf life of 55 Minas soft cheeses, commercially available in the Rio de Janeiro State, over the growth of bacteria of the Staphylococcus and Micrococcus genus were analyzed. The initial growth of Staphylococcus and Micrococcus spp., either in mixed or isolated culture, was obtained by standard methodology, in Colony Forming Units (CFU), or transformed in $\log _{10}$ for deşcriptive statistic and regression analysis. It was attributed log $=0$ (zero) to CFU $=0$. The effect of the independent variables $\mathrm{pH}$, humidity, and shelf life were tested individually and with all possible combinations, against the obtained CFU growth. By analyzing each variable alone, it was observed that humidity and cheese shelf life had little influence in bacteria growth $(p<0.01)$, with numerical values corresponding to $9.12 \%\left(r^{2}=0.0912\right)$ and $1.69 \%\left(r^{2}=0.0169\right)$, respectively. The $\mathrm{pH}$ had a significant influence of $23.89 \%\left(r^{2}=0.2389\right)$ over the CFU $(p<0.01)$. The best combination was obtained with the three variables associated, which explained an influence of $25.61 \%\left(r^{2}=0.2561\right)$. The low $p H$, low humidity and cheese short shelf life were associated with an increase of the CFU of Staphylococcus and Micrococcus spp. Statistical results from descriptive statistic and linear regression are tabulated.
\end{abstract}

Keywords: soft cheese, Staphylococcus, $\mathrm{pH}$, humidity, shelf life.

* DVM, MSc, Ph.D., Pesquisador III, Embrapa Agroindústria de Alimentos, Av. das Américas 29501, Guaratiba, CEP 23020-470 - Rio de Janeiro, RJ. E-mail: graca@ctaa.embrapa.br

** DVM, MSc., PhD, PD., Prof. titular, Departamento de Patologia Clínica Veterinária-UFF, R. Vital Brazil Filho, 64, CEP 24230-340, Niterói - RJ. Email: mironascimento@hotmail.com

*** DVM, Mestranda em Medicina Veterinária Preventiva (1998-2000), UFRRJ, Seropédica, RJ; Secretaria de Agricultura, Araruama - RJ.

**** DVM, MSc, Fundação Educacional D. André Arcoverde, Centro de Ensino Superior de Valença, Rua Sargento Vítor, 161, CEP 27600-000, Valença - RJ., E-mail: czarden@hotmail.com 


\section{Introdução}

Os alimentos são necessários para a sobrevivência e bemestar do homem e dos animais. Além de nutritivo, o alimento deve ser seguro para o consumo. A pior ameaça para o consumidor é um alimento contaminado com microrganismos, uma vez que podem causar deterioração e intoxicação, dependendo do microrganismo presente. A grande maioria dos alimentos causadores de enfermidades é de origem animal, incluindo os queijos, carnes, leite, ovos, pescados e maris$\cos$ (Neto, 1999). A redução dos riscos potenciais é o primeiro passo para se dispor de um alimento inócuo (Neto, 1999). Esses riscos podem ser biológicos, químicos e físicos.

Os microrganismos diferem muito na habilidade de se adaptarem aos meios e o crescimento é afetado principalmente pelo $\mathrm{pH}$, atividade aquosa e temperatura (Prescott et al., 1993). $A$ atividade aquosa geralmente diminui durante 0 processamento dos queijos, pela perda de água por evaporação ou por um aumento de substâncias solúveis em água, resultantes da degradação de proteína (Spahr e Url, 1994). No presente estudo, verificou-se percentagem de água de cada amostra de queijo examinada.

O pH é um termo usado para descrever a acidez ou alcalinidade de uma solução e tem um profundo efeito no crescimento dos microrganismos (Katsuyama, 1980). É uma medida da atividade do íon de Hidrogênio de uma solução e é definido como o logaritmo negativo da concentração do íon de Hidrogênio (Prescott et al., 1993). Isto significa que cada unidade na escala de $\mathrm{pH}$ representa uma troca decimal na concentração do íon de Hidrogênio.

Os Staphylococcus aureus (S. aureus) são significantes patógenos, destacados entre as bactérias que compõem os perigos biológicos (Neto, 1999). O limite mínimo de $\mathrm{pH}$ para crescimento de $S$. aureus de origem alimentar tem sido descrito por alguns autores como pH 4,5 (Katsuyama, 1980), de 4,0 a 4,7 (Franco e Landgraf, 1996) e de 5,0 a 6,0 (Prescott et al., 1993). Os padrões microbiológicos de alimentos de acordo com a Resolução no 12 de 2001 (ANVISA, 2001), para os queijos tipo minas frescal obedecem a critérios diferentes, dependendo do grau de umidade em relação aos limites e tolerâncias da população de Staphylococcus coagulase positiva/g de queijo-minas frescal, que substituiu a determinação de $S$. aureus, considerando $m=10^{2}$ e $M=10^{3}$ para o tipo de "alta a muita umidade" (46\% a $55 \%)$ e $m=10^{2}, M=5 \times 10^{2}$, para o tipo enquadrado como "de muito alta umidade" (umidade $>55 \%$ ) e não faz referência ao $\mathrm{pH}$.

O tempo de prateleira estabelecido para um alimento pode ser definido como o tempo entre a produção e a embalagem final do produto e o ponto no qual ele se torna inaceitável, sob condições ambientais definidas (Ellis, 1994). O tempo de prateleira ou tempo de validade dos queijos-minas frescal, como na maioria dos alimentos, vem rotulado na embalagem. Porém, esse prazo de validade só terá valor se o alimento estiver estocado dentro da faixa de temperatura adequada. A temperatura do ambiente afeta profundamente os microrganismos, cujo metabolismo é mais ativo em temperaturas mais elevadas, onde eles crescem mais rapidamente (Prescott et. al., 1993).

O presente trabalho objetivou verificar, através de análise estatística, a existência de relação entre a população de bactéri- as pertencentes aos gêneros Staphylococcus (incluindo as espécies coagulase positiva) e Micrococcus com o pH, umidade e tempo de prateleira, dos queijos tipo minas frescal.

\section{Material e métodos}

Para o presente estudo, foram examinados 55 queijos tipo minas frescal, no período de maio de 1998 a maio de 1999. Os queijos foram comprados em supermercados ou diretamente de propriedades rurais; no estado do Rio de Janeiro.

O método de análise microbiológica utilizado seguiu as recomendações do APHA (American Public Health Association, 2001). Pesou-se, assepticamente, $25 \mathrm{~g}$ de cada amostra e, após homogeneização em $225 \mathrm{~mL}$ de água peptonada a $0,1 \%$, por dois minutos, procedeu-se a diluições decimais, até $10^{-5}$, usando-se o mesmo tipo de diluente. A seguir, foram efetuadas inoculações $(0,1 \mathrm{~mL})$, em duplicatas, de cada diluição, em placas contendo meios de Ágar Baird Parker e Ágar Vogel Jonhson, com o auxílio de alça de Drigalski e mesa giratória. Após cultivo, as placas foram incubadas a $37^{\circ} \mathrm{C}$, por 24 a 48 horas. A contagem de colônias típicas em Unidades Formadoras de Colônias por g (UFC/g) e a identificação dos gêneros Staphylococcus e Micrococcus, em populações individuais ou mistas, obedeceu aos critérios padrões (Anonymous, 1987) obtendo-se a média das placas com crescimento.

A determinação do pH foi obtida em potenciômetro, após homogeneização de 10 gramas de cada amostra em $20 \mathrm{~mL}$ de água destilada. Como não foi possível determinar se a atividade aquosa, ou seja, a quantidade de água disponivel para o crescimento microbiano, verificou-se a percentagem de água de cada amostra de queijo examinada. A percentagem de água foi obtida pesando-se 10 gramas de cada amostra e expondo-a à temperatura de $140^{\circ} \mathrm{C}$ por duas horas, de acordo com a metodologia previamente descrita (Nascimento et al., 1998).

O tempo de prateleira usado nas análises foi calculado pela diferença entre o dia que cada amostra foi examinada e sua data de fabricação, ainda dentro da faixa de aceitabilidade da validade registrada na embalagem.

Usou-se estatística descritiva (média, mediana, valores máximo e mínimo) e análise de regressão linear. Para essas análises, o crescimento bacteriano, obtido em Unidades Formadores de Colônias/g de queijo, foi transformado em $\log _{10}$ e, no caso de UFC $=0$, considerou-se $\log =0$. A análise de regressão linear testou todas as associações possíveis. $\mathrm{Na}$ primeira etapa testou-se a relação do crescimento de Staphylococcus elou Micrococcus, com cada variável, $\mathrm{pH}$, percentagem de umidade e tempo de prateleira, obtidos dos 55 queijos, separadamente. As mesmas variáveis foram testadas em diferentes associações, para verificar efeito sinérgico e qual seria a melhor combinação para explicar o maior número de UFC.

\section{Resultados e discussão}

Os resultados da análise estatística descritiva dos dados dos 55 queijos referentes ao $\mathrm{pH}$, umidade, tempo de prateleira e UFC/g de bactérias pertencentes aos gêneros Staphylococcus e/ou Micrococcus, revelaram médias aritméticas, respectivamente, de $5,53 \pm 0,66 ; 60,98 \% \pm 7,12,10,47 \pm 5,41$ e 4,68 UFC/g $\pm 2,58$ (Tabela 1$)$. 
Tabela 1 - Resultados da análise estatística descritiva do $\mathrm{pH}$, umidade, tempo de prateleira e crescimento bacteriano (UFC de Staphylococcus e/ou Micrococcus) de 55 queijos-minas frescal

\begin{tabular}{ccccc}
\hline & $\begin{array}{c}\text { UFC } \\
(\log )\end{array}$ & $\mathrm{pH}$ & $\begin{array}{c}\text { Umidade } \\
(\%)\end{array}$ & $\begin{array}{c}\text { Tempo de } \\
\text { prateleira* (dias) }\end{array}$ \\
\hline Média & 4,68 & 5,53 & 60,98 & 10,47 \\
Desvio-Padrão & 2,58 & 0,66 & 7,12 & 5,41 \\
Coef. de Variação & 55,11 & 12,01 & 11,68 & 51,63 \\
Mediana & 5,51 & 5,59 & 59,70 & 10,00 \\
Valor Mínimo & $0,00^{\star \star}$ & 4,20 & 43,60 & 1,00 \\
Valor Máximo & 8,71 & 6,54 & 79,60 & 25,00 \\
\hline
\end{tabular}

* Foram analisados dados referentes a 47 queijos para tempo de prateleira (somente 47 continham data de fabricação e validade).

** Atribuiu-se UFC $=0,00$ para crescimento igual a zero, para cálculo do log.

Analisando-se as variáveis isoladamente, os resultados revelaram que a umidade e tempo de prateleira tiveram pouquissima influência na carga bacteriana $(p<0,01)$, com valores correspondentes, respectivamente, a $9,12 \%\left(r^{2}=0,0912\right)$ e $1,69 \%\left(r^{2}=0,0169\right)$. $O \mathrm{pH}$ teve uma influência maior, de $23,89 \%\left(r^{2}=0,2389\right)$ nas UFC $(p<0,01)$. A melhor combinação, que explicou cerca de $25,61 \%\left(r^{2}=0,2561\right)$ de crescimento de Staphylococcus e Micrococcus foi na análise com as três variáveis associadas: $\mathrm{pH}$, umidade e tempo de prateleira (Tabela 2). Porém, a influência do $\mathrm{pH}$ e da umidade sobre as UFC foi evidenciada por uma relação inversa (Tabela 3 ), ou seja, o pH e a umidade baixos desfavoreceram o crescimento de Staphylococcus e/ou Micrococcus nos queijos sob estudo. Embora pareça contraditório, pode-se explicar a relação do $\mathrm{pH}$ baixo com elevada contagem bacteriana, pois essa elevada contagem pode ser justificada por uma contaminação inicial dos queijos, acrescida pelo acondicionamento inadequado, possivelmente em temperatura imprópria e $\mathrm{pH}$ elevado, possibilitando que as bactérias pertencentes aos gêneros Staphylococcus e/ou Micrococcus crescessem e, conseqüentemente, acidificassem os -queijos, fato comprovado no momento das análises bacteriológicas. Dessa forma, por ocasião da coleta para exame bacteriológico, é provável que a fase logarítmica encontrava-se no platô ou início da fase de declínio e o pH baixo. Os Staphylococcus e/ou Micrococcus são bactérias fermentadoras que acidificam rapidamente o meio e a umidade, apesar de contribuir para o crescimento das bactérias, quando em nivel elevado, pode inibir esse crescimento.

Tabela 2 - Resultados da regressão linear de crescimento bacteriano (UFC/g Staphylococcus/Micrococcus) com todas as possíveis combinações de $\mathrm{pH}$, umidade e tempo de prateleira em 47 queijos-minas frescal

\begin{tabular}{ccc}
\hline $\mathrm{P}$ & $\mathrm{r}^{2}$ & \multicolumn{2}{c}{ Modelo das variáveis $^{*}$} \\
\hline 1 & 0,0169 & A \\
2 & 0,0912 & B \\
3 & 0,2389 & C \\
4 & 0,0943 & A B \\
5 & 0,2413 & A C \\
6 & 0,2520 & B C \\
7 & 0,2561 & A B C \\
\hline
\end{tabular}

$P=$ possiveis combinações; "Variáveis independentes:

$A=$ tempo de prateleira; $B=$ umidade; $C=p H$
De acordo com os resultados, observou-se que, à medida que $\circ \mathrm{pH}$ e a umidade aumentavam, havia um decréscimo de 1,88 e 0,058 UFC/g das bactérias sob estudo, respectivamente, para as variáveis citadas (Tabela 3 ). Por outro lado, foi confirmado que à medida que o tempo de estocagem aumentou, houve apenas um pequeno aumento no número de Staphylococcus e/ou Micrococcus nos queijos, cuja associação pode ser desconsiderada $\left(r^{2}=0,0169\right)$. O fato de se ter usado queijos sem ultrapassar o prazo de validade, não nos deu um resultado de uma maior associação entre tempo de prateleira e UFC/g, visto que só foram analisadas as variações de diferentes tempo de prateleira dentro do periodo de validade.

Tabela 3 - Resultado da análise de regressão linear de crescimento bacteriano (UFC) de Staphylococcus e/ou Micrococcus em relação às variáveis independentes $\mathrm{pH}$, umidade e tempo de prateleira, em 47 amostras de queijos-minas frescal

\begin{tabular}{lc}
\hline Variáveis & Coeficiente \\
\hline Constante & 18,156 \\
$\mathrm{pH}$ & $-1,8791$ \\
Umidade & $-0,0584$ \\
Tempo de prateleira & 0,0342 \\
\hline
\end{tabular}

Casos incluidos (que continham tempo de prateleira) $=47$

Graus de liberdade $=43$

$\mathrm{F}$ total $=4,9335$

$r^{2}=0,2561$

$p=0,49$

A influência do $\mathrm{pH}$ sobre o crescimento bacteriano não é um fato novo (Katsuyama, 1980; Franco e Landgraf, 1996), porém os padrões microbiológicos dos alimentos referidos no Decreto $n \circ 12$ (Brasil, 2001) fazem apenas menção à umidade dos queijos em relação ao crescimento microbiano. No presente estudo, embora a umidade das amostras tenha sido bastante variada, não mostrou ter uma influência tão significativa no crescimento de Staphylococcus e/ou Micrococcus, o que pode significar que, embora presente nos queijos, pode estar adsorvida e não disponível para o crescimento potencial dos microrganismos. Entretanto, ao contrário da umidade, a influência do $\mathrm{pH}$ foi significativa, embora não conste no citado Decreto como variável controlada para o crescimento de Staphylococcus coagulase positiva, o que seria motivo de investigações futuras visando melhorar a qualidade microbiológica do alimento sob estudo, pois as bactérias patogênicas são uma ameaça não só para o consumidor, como também podem trazer prejuizos para as empresas. Esse parâmetro é importante e deveria ser inserido na Legislação vigente. Outros fatores podem estar também influenciando a qualidade final dos queijos-minas frescal.

\section{Conclusões}

$\mathrm{O}$ baixo $\mathrm{pH}$ dos queijos tipo minas frescal desfavoreceu 0 desenvolvimento de Staphylococcus e Micrococcus. A grande diversidade de umidade nos queijos tipo minas frescal não influenciou o crescimento de Staphylococcus e/ou Micrococcus. As variações de tempo de prateleira, dentro do prazo de validade, não afetaram o crescimento. 


\section{Agradecimentos}

Apoio financeiro da Embrapa, CNPAB (Subprojeto n 10.0.94.746-10) e suporte inicial do CNPq (Projeto no 530148/93-5).

\section{Referências}

ANONYMOUS. Staphylococcus isolation and identification. In: Food Science and Tecnology 104L, Laboratory Syllabus. Davis, California. U.C.Davis, 1987. 104 p.

ANVISA - Agência Nacional de Vigilância Sanitária. Legislação - Resolução-RDC $n^{\circ}$. 12, de 2 de janeiro de 2001. Padrões microbiológicos sanitários para alimentos. Secretaria de Vigilância Sanitária. Anexo I, p. 54.

APHA-AMERICAN PUBLIC HEALTHASSOCIATION. 2001. Committee on Microbiological Methods for Foods. Compendium for the Microbiological Examination of Foods. 4. ed. Washington: Sheridan Books, Inc. 2001. 1219 p. DOWNES, F.P.; ITO, K. (Ed.), ISBN: 087553175-X.

ELLIS, M.J. The methodology of shelf life determination. 1994. In: Shelf life evaluation of foods. C.M.D. Man \&A.A. Jones eds. BlackieAcademic \& Professional. p. 27-34, 1994.
FRANCO, B.D.GM; LANDGRAFT, M. Microbiologia dos alimentos. Rio de Janeiro: Atheneu, 1996. 182 p.

KATSUYAMA, A.M.; STRACHAN, J.P. Principles of food processing sanitation. Washington D.C.: The Food Processing Institute, ed., 1980. $303 \mathrm{p}$.

NASCIMENTO, M.G.F.; CUNHA, C.P.; CORBIA,A.C.G; JESUS, V.L.T.; LIGNON, G.B.; OLIVEIRA, C.Z.F. Análise microbiológica e determinação da umidade e pH de queijos tipo minas frescal. In: JORNADA DE INIClAÇĀO CIENTíFICA DA UFRRJ, 8., 1998, Seropédica, RJ. Anais... Seropédica, UFRRJ, 1998. p. 205-206.

NETO, R.O.T. Um alimento inócuo é fruto de respeito. Rev. B.Q. Qualidade, n. 85, p. 96-106, junho 1999.

PRESCOTT, L.M.; HARLEY, J.P. \& KLEIN, D.A. (Eds)Micobiology. 2nd. Ed. Wm.C. Brown Publishers, Chapter 6. Microbial Growth, (p.112132), 1993, p. 912.

SPAHR, U.; URH, B. Behavior of pathogenic bacteria in cheese-a synopsis of experimental data. Bulletin of Int. Dairy Fed., n. 298, p. 2-16, 1994. 